\title{
Dynamic Brain Function Monitoring a New Concept in Neuro-Intensive Care
}

\author{
E. Bosco and P. Zanatta \\ Department of Anesthesia and Intensive Care, Treviso Hospital \\ Italy
}

\section{Introduction}

Multimodality neuromonitoring has became increasingly complex, and although advances in neuromonitoring have provided insight into pathophysiology and physiological response to therapy, beneficial effects on patient outcomes have not been definitively established. The attitude towards the benefits of monitoring equipment has often been guided by wishful thinking. Rosner and colleague (Rosner MJ,1986) popularized the notion that cerebral perfusion pressure (CPP) should be aggressively managed at levels above $70-90 \mathrm{mmHg}$, if necessary by using vasopressors. At the same time, however, the "Lund concept" urged for a reduction of microvascular hydrostatic pressures to minimize oedema formation, accepting CPP as low as $50 \mathrm{mmHg}$ in adults (Grände PO,2002 ). Following an update of the Brain Trauma Foundation guidelines in 2003, the consensus target value for CPP has been set at $60 \mathrm{mmHg}$. Even so, the controversy described above exemplifies the frustrating lack of good evidence that is available to make rational treatment decisions in the setting of intracranial pressure (ICP)-guide care. It is important to consider that there is large heterogeneity within the head trauma population, the intracerebral hemorrhage, the subarachnoid hemorrhage and the physiopathology between them. Therefore it is possible that many commonly used interventions that are aimed to reduce intracranial hypertension are ineffective, unnecessary or even harmful for some patient at certain times, at certain values. There is an increasing awareness that an aggressive ICP and CPP targeted approach may result in cardiorespiratory complications. A key limitation in the demonstration of efficacy of monitoring in neurocritical care is the complexity of care generated by multimodality monitoring. If one considers continuously monitoring 10-20 interrelated physiological parameters in a modern neurocritical care unit and each parameter has 10 possible interventions, the enormous potential number of co-interventions represents a formidable challenge in clinical trial design. The application of continuous neurophysiological monitoring with somatosensory evoked potential (SEP) and electroencephalography (EEG) have an intuitive appeal, since these techniques yeald a direct measure of brain function in patients whose neurological status might otherwise be difficult to evaluate. The early components of SEP are used in the acute phase of cerebral damage when the patient, as result of sedatives, neuromuscular blockade or the severity of coma, is difficult to assess on a clinical level. Short latency SEP are largely resistant to analgo-sedation and have a waveform, which is easily interpretable and comparable in subsequent recordings. They have peripheral, spinal, brainstem and intracortical components, which are identifiable in all subject exploring an extended Cerebral Nervous 
System (CNS) pathway. In the absence of a relevant lesion along afferent sensory pathways, a "global" index of brain function (reflected of brainstem, thalamo-cortical and intracortical transmission in both emispheres) can be extrapolated from them. The concept of secondary insults occurring after the primary neurologic injury was put forth by Jennet and colleagues (Rose et al., 1977), Andrew et al. (1990) and later by Miller et al. (1994), who reported that the majority of patients (91\%) suffered secondary insults. The secondary insults that occurred most frequently were raised intracranial pressure, hypotension, and pyrexia. Moreover, several investigator have reported ongoing transient and dynamic changes in brain metabolism and neurochemistry (Bullock et al., 1995; Vespa et al., 2003) after brain injury. Continuous EEG monitoring is a valuable clinical instrument "to detect and protect"; to detect seizures and protect the brain from seizures-related injury in critically ill patients, whose brain are often in a particular vulnerable state.

\section{The Importance of the aetiology of coma}

\subsection{Anoxic coma}

The prognostic value of SEP patterns in anoxia is complex

Preserved short or middle-latency SEP do not prognosticate awakening with sufficient certainty, but absent cortical SEP are among the most powerful predictors of non-awakening from anoxic coma.

The bilateral absence of N20 in anoxic coma (and only in anoxic coma) is a very reliable indicator of poor prognosis,since none of the patients reported in literature did better than PVS. Therefore, this pattern provides strong information for decision making in intensive care .

\subsection{Head trauma}

Can be associated with both "primary" and "secondary" dysfunction.

Primary dysfunction can be a consequence of mechanical lesions, which are usually irreversible, of associated brain oedema, which may be reversible. Mechanical lesions can consist either of brain contusion or diffuse axonal lesions (white matter of the cerebral hemispheree, corpus callosum,midbrain).

Secondary dysfunction may be ischemic (systemic hypoperfusion),epileptic, or due to intracranial hypertension and its complications (transtenorial herniation,brain death).

Short latency SEP are normal in about $50 \%$ of cases. Moreover, in contrast with brain anoxia, in which it has no prognostic meaning,the observation of bilaterally normal short-latency SEP constitutes a favourable sign in head trauma (predictive positive value of awaikening of about $90 \%$ and $75 \%$ to $80 \%$ probability of good outcome). Level 1a abnormalities (Table I) are still a relatively good sign too ( $69 \%$ of good outcome). These situations with preserved short latency SEP include brain oedema and/or diffuse axonal lesion without brainstem involvement. By contrast, level 2 or 3 abnormalities have been associated with death or vegetative states in more than $90 \%$ of cases, and with severe disability in almost $100 \%$. Therefore, normal or absent cortical SEP are the strongest prognostic indicators, with an occurrence of about $70 \%$ in severly injured patients; 


\begin{tabular}{|c|c|c|}
\hline Level & Description & Remarks \\
\hline 0 & Normal & \\
\hline $1 \mathrm{a}$ & $\begin{array}{l}\text { Inter Peak Latency (IPL) increas without } \\
\text { peak distorsion }\end{array}$ & $\begin{array}{l}\text { Drugs,metabolic } \\
\text { disturbances,hypothermia,usually } \\
\text { reversible }\end{array}$ \\
\hline $1 b$ & $\begin{array}{l}\text { Distorsion or disappearance, without proof } \\
\text { of the integrity of the sensory receptors or } \\
\text { proximal afferent pathways }\end{array}$ & Uncertain pattern \\
\hline 2 & $\begin{array}{l}\text { Distorsion without disappearance, with } \\
\text { proof of the integrity of the sensory system }\end{array}$ & \\
\hline 3 & $\begin{array}{l}\text { Disappearance,with proof of the integrity } \\
\text { of the sensory system }\end{array}$ & \\
\hline
\end{tabular}

Table 1. Classification of short-latency EP abnormalities

\section{The EEG}

The electroencephalogram (EEG) provides a non invasive way to dynamically assess brain function. Recent advances in computer technology, networking, and data storage have made continuous EEG (cEEG) monitoring practical, and its use is common in many Neuro Intensive Care Unit (NICU). Methods for analyzing and compressing the vast amounts of data generated by cEEG have allowed neurophysiologists to more efficiently review recordings from many patients monitored simultaneously and provide timely information for guiding treatment. There are still many hurdles in making monitoring of brain function truly real time, reliable, practical, and widely available, but the technology is progressing rapidly. The most common reason for performing cEEG is to detect nonconvulsive seizures (NCSzs) or non convulsive status epilepticus (NCSE). Although previously thought to be uncommon NCSzs and NCSE are being recognized more frequently. The current indications and potential uses for cEEG in the critically ill are summarized in Table II

\begin{tabular}{|c|}
\hline 1.Detection of nonconvulsive seizures \\
\hline 2.Detection of convulsive status epilepticus \\
\hline $\begin{array}{l}\text { 3.Stereotyped activity such as paroxysmal movements, nystagmus, twitching, jerking, } \\
\text { hippus, autonomic variability }\end{array}$ \\
\hline 4. Monitoring of ongoing therapy: \\
\hline $\begin{array}{l}\text { a)Induced coma for elevated intracranial pressure or refractory status } \\
\text { epilepticus }\end{array}$ \\
\hline b) Assessing level of sedation \\
\hline 5. Ischemia detection: \\
\hline a)Vasospasm in subarachnoid hemorrhage \\
\hline b)Cerebral ischemia in other patients at high risk for stroke \\
\hline 6. Prognosis: \\
\hline a)Following cardiac arrest \\
\hline b)Following acute brain injury \\
\hline
\end{tabular}

Table 2. Indications for Continuous Electroencephalogram (cEEG) Monitoring (Friedman D et al.2009) 
NCSzs and NCSE are increasingly recognized as common occurrences in the ICU, where $8 \%-48 \%$ of comatose patients may have NCSzs, depending on which patients are studied. NCSzs are electrographic seizures with little or no clinical manifestations, so EEG is necessary for detection. NCSE occurs when NCSzs are prolonged; a common definition is continuous or near-continuous electrographic seizures of at least $30 \mathrm{~min}$ duration. The most common manifestation is a depressed level of consciousness.Most patients with NCSzs have purely electrographic seizures, but other subtle signs can be associated with NCSzs, such as face and limb myoclonus, nystagmus, eye deviation, pupillary abnormalities (including hippus), and autonomic instability.None of these signs are highly specific for NCSz, and they are often seen under other circumstances in the critically ill patient; thus, cEEG is usually necessary to diagnose NCSzs. The etiologies for NCSzs and NCSE in ICU patients are similar to the causes of convulsive seizures in these patients. These include acute structural lesions, infections, metabolic derangements, toxins, withdrawal and epilepsy, all common diagnoses in the critically ill patient (Table III). However, NCSzs are the more common ictal manifestation in ICU patients and should be considered when evaluating the cause of or contributors to altered mental status, especially in high-risk populations.

\begin{tabular}{|l|}
\hline a)Primary criteria \\
\hline Any pattern lasting at least 10 s satisfying any one of the following three primary criteria: \\
\hline $\begin{array}{l}\text {-Repetitive generalized or focal spikes, sharp-waves, spike-and-wave complexes } \\
\text { at 3/s }\end{array}$ \\
$\begin{array}{l}\text {-Repetitive generalized or focal spikes, sharp-waves, spike-and-wave or sharp- } \\
\text { and-slow wave complexes at 3/s and the secondary criterion }\end{array}$ \\
-Sequential rhythmic, periodic, or quasi-periodic waves at _1/s and unequivocal \\
evolution in frequency (gradually increasing or decreasing by at least 1/s, e.g. \\
2-3/s), morphology, or location (gradual spread into or out of a region \\
involving at least two electrodes). \\
-Evolution in amplitude alone is not sufficient. Change in sharpness without \\
other change in morphology is not enough to satisfy evolution in morphology \\
\hline $\begin{array}{l}\text { b)Secondary criterion } \\
\text { electroencephalogram (EEG)-patterns (such as posterior-dominant "alpha" rhythm) } \\
\text { temporally coupled to acute administration of a rapidly acting antiepileptic drug. }\end{array}$ \\
\hline $\begin{array}{l}\text { Resolution of the "epileptiform" discharges leaving diffuse slowing without clinical } \\
\text { improvement and without appearance of previously absent normal EEG patterns would } \\
\text { not satisfy the secondary criterion. }\end{array}$ \\
\hline $\begin{array}{l}\text { Adapted from Chong DJ, Hirsch LJ, J Clin Neurophysiol, 2005, 22, 79-91, who modified } \\
\text { the criteria of Young et al.13 }\end{array}$ \\
\hline
\end{tabular}

Table 3. Criteria for Nonconvulsive Seizure (Chong DJ et al.,2005)

\section{Which patients are most likely to have nonconvulsive seizures?}

In our experience subarachnoid haemorrhage with severe vasospasm shows a higher incidence of epileptiform discharge $24-48$ hours before detection of vasospasm Table IV 


\begin{tabular}{|c|c|c|c|c|c|}
\hline Study & Study population & $\begin{array}{l}\text { EEG } \\
\text { type }\end{array}$ & Design & $N$ & $\begin{array}{l}\text { Percentage } \\
\text { of patients } \\
\text { with any } \\
\text { seizures }(\%)\end{array}$ \\
\hline Jordan & Neuro ICU patients & cEEG & Retrospective & 124 & 35 \\
\hline De Lorenzo et al. & prior convulsive SE & cEEG & Prospective & 164 & 48 \\
\hline Vespa et al. & $\begin{array}{l}\text { moderate to severe } \\
\text { traumatic brain injury }\end{array}$ & cEEG & Prospective & 94 & 22 \\
\hline Vespa et al. & $\begin{array}{l}\text { stroke or intracerebral } \\
\text { hemorrhage. }\end{array}$ & cEEG & Retrospective & 109 & 19 \\
\hline Claassen et al. & $\begin{array}{l}\text { decreased level of } \\
\text { consciousness or } \\
\text { suspected } \\
\text { subclinical seizures. }\end{array}$ & cEEG & Retrospective & 570 & 19 \\
\hline Pandian et al. & Neuro ICU patients & cEEG & Retrospective & 105 & 68 \\
\hline Jette & $\begin{array}{l}\text { Patients_18 yr old with } \\
\text { suspected } \\
\text { subclinical seizures. }\end{array}$ & cEEG & Retrospective & 117 & 44 \\
\hline Claassen et al. & $\begin{array}{l}\text { Patients with } \\
\text { intracerebral } \\
\text { hemorrhage }\end{array}$ & cEEG & Retrospective & 102 & 31 \\
\hline Oddo et al. & $\begin{array}{l}\text { suspected } \\
\text { subclinical seizures }\end{array}$ & cEEG & Retrospective & 201 & 27 \\
\hline Bosco et al. & $\begin{array}{l}\text { Subarachnoid } \\
\text { hemorrhage with severe } \\
\text { vasospasm }\end{array}$ & cEEG & Retrospective & 68 & 35 \\
\hline
\end{tabular}

Table 4. Studies Using Continuous Electroencephalogram (EEG) Monitoring in Critically Ill Patients for Detection of Nonconvulsive Seizures

\section{Cost-effectiveness}

Little information is available regarding the cost-effectiveness of cEEG monitoring. In part, this is due to the early stage of development of this technique. This also is related to rapid changes in the technology used to perform cEEG monitoring. Each year provides new capabilities, often at decreased overall cost, making timely assessment of cost-effectiveness difficult. Vespa PM et al.assessed available data from their monitoring experience at UCLA, and concluded that cEEG accounted for only $1 \%$ of hospital costs and, during its use, significantly affected critical decision making in $>90 \%$ of 300 patients who underwent monitoring.They concluded, "cEEG is cost-effective and appears to offer additional quality to intensive care." Claassen et al evaluating their experience in 15 patients undergo cEEG for evaluation of status epilepticus or nonconvulsive seizures associated with altered consciousness, determined that cEEG monitoring influenced clinical management-usually decisively - in 50 of 109 monitoring days. Assessing the cost-effectiveness of cEEG will, however, remain a difficult task. This is because the technology and capabilities continue to evolve rapidly, and because, given the clear diagnostic and therapy-guiding benefits evident to many patients undergoing monitoring, randomization of comatose and obtunded patients to receive or forego such monitoring may not be ethical. 


\section{Methods (from a personal experience of continuous EEG-SEP monitoring in Neurosurgical Intensive Care of Treviso Hospital Italy 2007-2009)}

Quantitative brain function monitor consisted of an EEG-SEP recording system located far from the patient bedside connected by a serial interface to a small amplification head box with 28 channels and a multimodal stimulator (NEMUS-EB Neuro, Italy) FIG 1. The acquired data were transmitted to the PC by means of optical fiber. This software allows the setting of cycles of SEP for each channel obtained to electrical stimulation of the right and left median nerve at the wrist. We used straight stainless steel needle electrodes. Stimulus intensity was set above motor threshold (15-20 mAmp), pulse duration was 0,2 ms; stimulus rate $3 \mathrm{~Hz}$. Electrodes were placed at Erb's point (referred to posterior muscle), spinous process Cv7 (referred to anterior neck), P3 and P4 (referred both to Fz). Time base was 100 ms; bandwidth $5 \mathrm{~Hz}-3 \mathrm{KHz}$. An average of 200 responses were repeated and superimposed. The length of the SEP session was set through a user-defined macro. We used a recording macro of 12 minutes of EP every 50 minutes. EEG was recorded continuously. We recorded a first trace of EP as the template, to which the following traces were compared. We manually located the markers of the principal waves (N20 latency and N20-P25 amplitude), than we started the session. The software automatically recognize N20 and P25 peaks and puts the marker on the maximum negative and positive deflection within a narrow window of $\pm 1 \mathrm{msec}$. Traces are displayed in cascades on one side of the screen, while the trends of SEP latencies and amplitude are displayed on the other side. A horizontal baseline represents latency and amplitude of the template; latency and/or amplitude modifications cause the lines diverge from baseline. Digital EEG is acquired through eight electrodes at the location $\mathrm{F} 3, \mathrm{C} 3, \mathrm{~T} 3, \mathrm{P} 3, \mathrm{~F} 4, \mathrm{C} 4, \mathrm{~T} 4, \mathrm{P} 4$ of the International 10-20 System. These are referred to a reference electrode at midpoint between $\mathrm{Fz}$ and $\mathrm{Cz}$. The needles were covered with a plastic transparent dressing. According to Amantini et al SEP of each side were graded on a 3-point scale as normal (N) if cortical complex N20/P25 amplitude and central conduction time (CCT) were normal $\left(1,2 \mathrm{mcV}=5^{\circ}\right.$ percentile); pathological (P) if CCT was prolonged and /or $\mathrm{N} 20 / \mathrm{P} 25$ amplitude was $<1,2 \mathrm{mcV}$ or the left-right amplitude asymmetry was greater than $50 \%$; absent (A) if cortical responses were absent with preserved N13. Taking into account responses in both hemispheres, 6 patterns were defined: NN, NP, PP, AN, AP and AA. We used an electroencephalographic classification for coma based on Synek modificated system (Synek VM 1988). According to this, all the recordings were reviewed and classified, by a single expert EEGer in:

\begin{tabular}{|l|}
\hline IA-Delta/theta $>50 \%$ reactivity, \\
\hline IB-Delta/theta $>50 \%$ without reactivity, \\
\hline II-Triphasic waves, \\
\hline IIIA-Burst suppression with epileptiform activity, \\
\hline IIIB-Burst suppression without epileptiform activity, \\
\hline IV-Alpha/theta/spindle coma unreactive, \\
\hline VA-Epileptiform activity Generalized, \\
\hline VB-Epileptiform activity focal or multifocal, \\
\hline VIASuppression $<20 \mathrm{mcV}$, but $>10 \mathrm{mcV}$, \\
\hline VIBsuppression $<10 \mathrm{mcV}$. \\
\hline
\end{tabular}




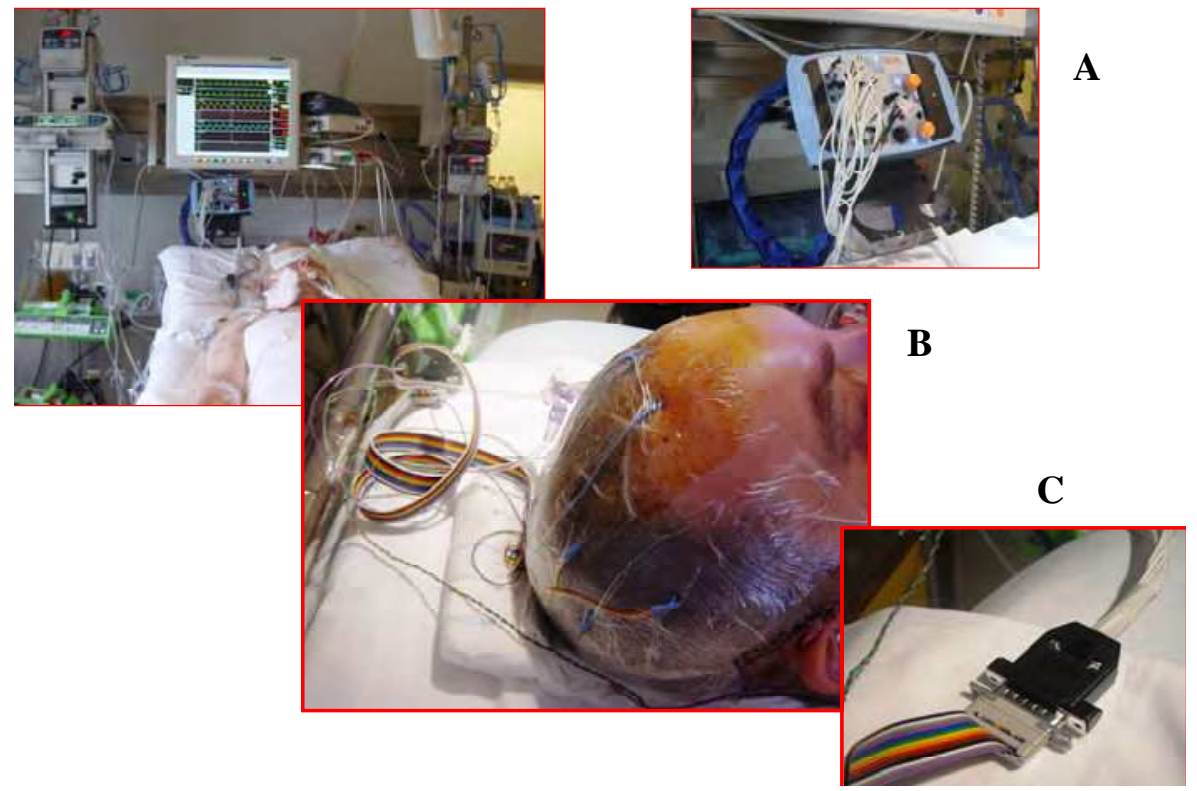

Fig. 1. Example of continuous EEG-SEP monitoring setting in ICU

A-Small amplification head-box with 28 channels and a multimodal stimulator

(NEMUS-EB Neuro, Italy)The acquired data are transmitted to the PC by means of an optical fiber.

B-We use straight stainless steel needle electrodes these are gathered in plaits of colored strings.The needles were covered with a plastic transparent dressing

C-Plug-in to deconect the patient

EEG traces were displayed on one side of the screen, and quantitative elettroencephalographic (QEEG) on the other side. QEEG consists of both frequency Color Spectral Density Array (CDSA) and amplitude (percentage of burst-suppression) analysis. The ICP was monitored with a an intraventricular catheter. ICP, CPP, Mean artery pressure (MAP) were stored in a database file. From these informations, the peak ICP level and the time of its occurrence were established for each patient during the monitoring period. In the SAH, Transcranial Doppler (TCD) was used for detecting vasospasm and guiding therapy. TCD monitoring by using bilateral $2 \mathrm{MHz}$ Probes with probe holder were lasted at least 30 minutes per day through temporal windows and eye windows to explore the cerebral arteries flow. Vasospasm was diagnosed in the presence of TCD mean velocities above $120 \mathrm{~cm} / \mathrm{s}$ (or a daily change in mean transcranial Doppler velocities of $>50 \mathrm{~cm} / \mathrm{s}$ ) or angiographic arterial narrowing. Patients were treated with a standard protocol including intravenous muscle relaxants, mechanical ventilation, osmotic diuresis and cerebrospinal fluid (CSF) drainage for elevations in ICP $>20$ $25 \mathrm{mmHg}$. The respective lengths of EEG and SEP sessions were decided on the basis of clinical features. Monitoring went on until the monitorated parameters were stable and the patient was no more considered at risk of developing brain complications. Acquired data were saved on the recording remote PC used as a server. A follow up telephone interview was conducted at least 3 month after discharge from the hospital. The outcome was assessed using the 5 point Glasgow Outcome Scale (GOS,Jennet and Bond,1975). 


\section{Statistical analysis}

Our interest focused on assessing the degree to which level of SEP and EEG monitoring predicts GOS levels, in particular considering evolutions in time, independently from other concomitant variables. Hence, we fitted a model in which the ratio between probability that GOS shows a certain level and the probability to observe a lower level depends on levels and changes in SEP and EEG by taking into account the joint effect of other related variables. A proportional odds model (e.g. Agresti, 2002) has been fitted to data, by assuming, as reasonable first approximation, that the effect of each variable does not vary with the CGS score at admittance. We also fit a binary logistic model (e.g. Agresti, 2002) to estimate the effect of monitors on the probability of dying (GOS equal to 1). Both families of models, logistic and proportional odds, have been fitted by Maximum Likelihood and the partial effect of each variable has been tested by Likelihood Ratio test.

\section{Results}

A total of 68 patients (34 males and 34 females, mean age $53.19 \pm 14.44$ years, range 18-83 years) were monitored with continuous EEG-SEP for an average of $10 \pm 4$ days and were included in the study. We observed that in all the patients who were clinically stable SEP never showed modification in latency or amplitude. On the contrary, whenever a neurological deterioration occurred with GCS decrease (in 20 patients, 29,4\%) SEP always showed significant increase in latency and decrease in amplitude. In these 20 patients the EEG-SEP worsening was not correlated with an immediate increased ICP. In 16 out of 20 patients EEG-SEP worsening appeared $24-48$ hours before ICP rising. These patients had developed angiographic vasospasm with ischemic lesion at CT Scan. Moreover, EEG-SEP worsening appeared after ICP increase in 4 patients with brain swelling documented at a serial CT scan. In the first 16 patients, analysis of EEG showed nonconvulsive seizures with periodic discharges and rhythmic delta activity in a range of 48 hours before a documented TCD and angiographyc vasospasm. After EEG epileptiform discharge, SEP showed an instability of amplitude with increments and decrements upper $50 \%$ of baseline with a final reduction or dissapereance of cortical SEP (Fig II and Fig III). These patients documented cortical ischemia at a serial CT scan (TableV).

\begin{tabular}{|c|c|c|c|c|c|c|c|c|}
\hline & $\begin{array}{c}\text { No of } \\
\text { patients }\end{array}$ & $\begin{array}{l}\text { SEP } \\
\text { Stable }\end{array}$ & $\begin{array}{l}\text { Decrease } \\
\text { SEP } \\
\text { BEFORE } \\
\text { ICP } \\
\text { increase }\end{array}$ & $\begin{array}{l}\text { Decrease } \\
\text { SEP } \\
\text { AFTER } \\
\text { ICP } \\
\text { increase }\end{array}$ & $\begin{array}{c}\text { No of } \\
\text { Vasospasm }\end{array}$ & $\begin{array}{c}\text { Epileptiform } \\
\text { discharge(periodic } \\
\text { discharges,rhythmic } \\
\text { delta activity,spike- } \\
\text { wave or sharp-Wave) }\end{array}$ & $\begin{array}{c}\text { Increase } \\
\mathrm{ICP}>25 \mathrm{mmHg}\end{array}$ & $\begin{array}{l}\text { CTscan } \\
\text { Secondary } \\
\text { damage }\end{array}$ \\
\hline SAH & $\begin{array}{c}51 \\
(75 \%)\end{array}$ & $\begin{array}{c}35 \\
(68,6 \%)\end{array}$ & $16(31,4 \%)$ & 0 & $\begin{array}{c}16 \\
(31,4 \%)\end{array}$ & $\begin{array}{c}18 \\
(35,2 \%)\end{array}$ & $\begin{array}{c}27 \\
(52,9 \%)\end{array}$ & $\begin{array}{c}18 \text { ischemic } \\
\text { lesion }\end{array}$ \\
\hline ICH & $\begin{array}{c}17 \\
(25 \%)\end{array}$ & $\begin{array}{c}13 \\
(76,5 \%)\end{array}$ & 0 & $\begin{array}{c}4 \\
(23,5 \%)\end{array}$ & 0 & $\begin{array}{c}6 \\
(40 \%)\end{array}$ & $\begin{array}{c}12 \\
(70,5 \%)\end{array}$ & $\begin{array}{c}12 \text { mass } \\
\text { effect }\end{array}$ \\
\hline tot & $\begin{array}{c}68 \\
(100 \%)\end{array}$ & $\begin{array}{c}48 \\
(70,5 \%)\end{array}$ & $\begin{array}{c}16 \\
(23,5 \%)\end{array}$ & $\begin{array}{c}4 \\
(5,8 \%)\end{array}$ & $\begin{array}{c}18 \\
(26,4 \%)\end{array}$ & $\begin{array}{c}24 \\
(35,2 \%)\end{array}$ & $\begin{array}{c}39 \\
(57,3 \%)\end{array}$ & $\begin{array}{c}30 \\
(48,5 \%)\end{array}$ \\
\hline
\end{tabular}

Table 5. Temporal analysis of ICP and EEG worsening related to ICP increase, vasospasm and CT scan ischemic evidence. 

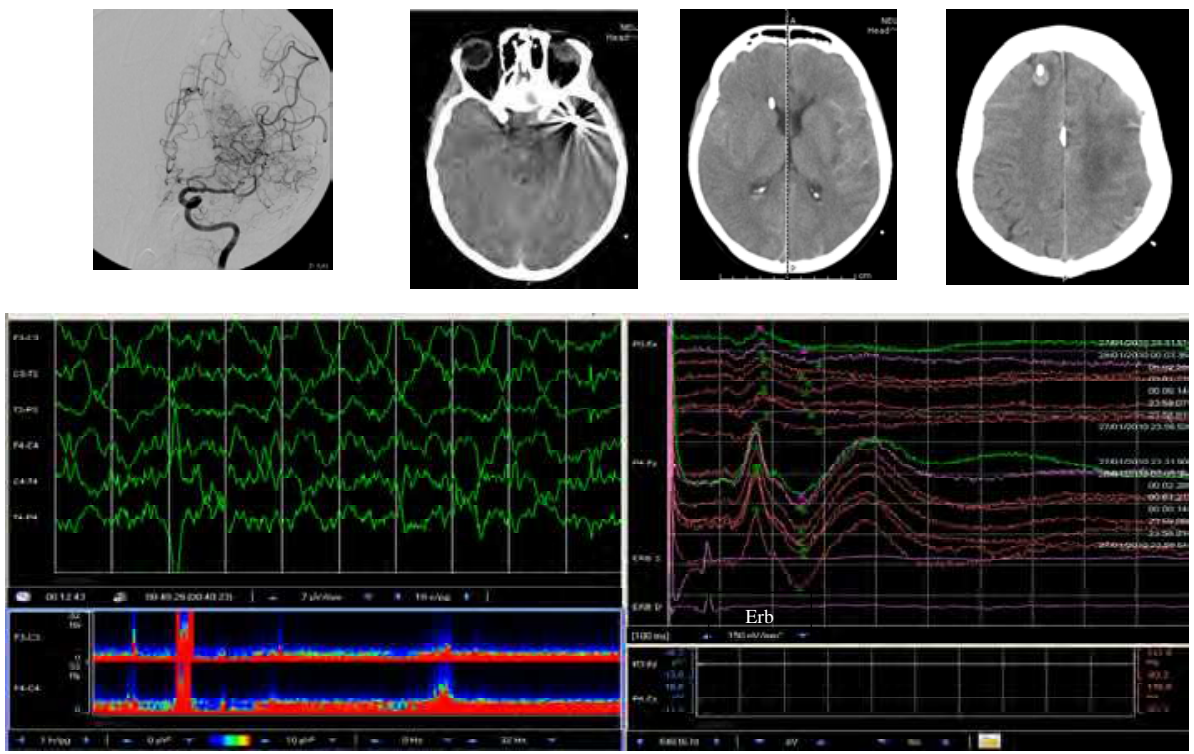

Fig. 2. Multimodality monitoring for vasospasm after subarachnoid hemorrhage (SAH): SEP traces and trend, on right and with raw EEG and CDSA, on left. Angiographic vasospasm with ischemic lesion at CT Scan upper screen

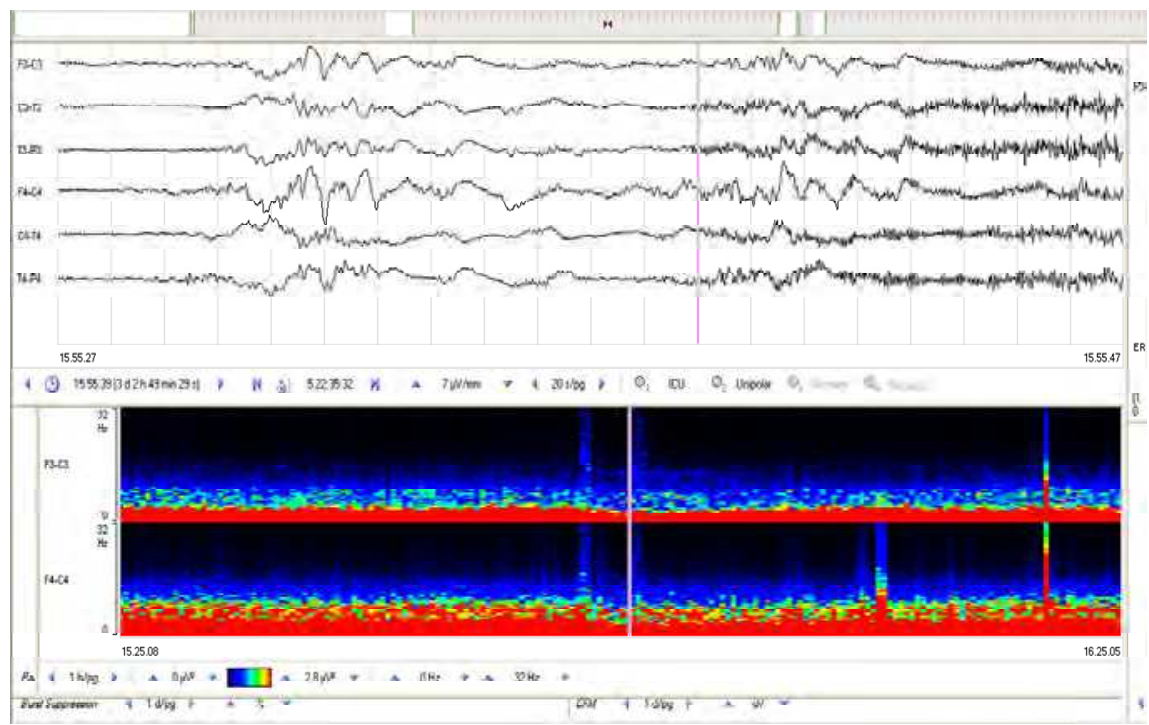

Fig. 3. The EEG segment documents a nonconvulsive seizure discovered during an EEG performed to evaluate a 62-year-old women with subarhanoic hemorrhage Clinical seizure activity was not evident despite the repetitive occurrence of electrographic seizures. Continuous EEG monitoring was initiated to evaluate the effects of therapy. 
In the table VI we show the p-values obtained by univariate association tests.

\begin{tabular}{|l|l|l|}
\hline Variable & Association with GOS & $\begin{array}{l}\text { Association with } \\
\text { mortality }\end{array}$ \\
\hline Age & 0.637 & 0.363 \\
Duration & 0.253 & 0.037 \\
Gender & 0.488 & 0.183 \\
CGS-M & $<0.001$ & $<0.001$ \\
EEG initial & 0.717 & 0.205 \\
EEG second & 0.747 & 0.214 \\
EEG final & 0.136 & 0.002 \\
SEP initial & 0.001 & 0.514 \\
SEP second & 0.002 & 0.152 \\
SEP final & $<0.001$ & $<0.001$ \\
EEG from first to second time & 0.766 & 0.349 \\
interval (worsened) & & 0.001 \\
EEG from second to third time & 0.012 & 0.001 \\
interval (worsened) & & 0.221 \\
EEG from first to third time interval & 0.005 & $<0.001$ \\
(worsened) & & $<0.001$ \\
SEP from first to second time & 0.227 & 0.734 \\
interval (worsened) & & 1 \\
SEP from second to third time & $<0.001$ & 0.215 \\
interval (worsened) & 0.001 & $<0.001$ \\
SEP from first to third time interval & 0.275 & \\
(worsened) & 0.252 & \\
Embolization & 0.407 & \\
Craniotomy & 0.007 & \\
Cr. Dec & & \\
ICP & 0.75 & \\
\hline
\end{tabular}

Table 6. Univariate association measures: p-values

We included in the logistic model all the available variables: age, sex, initial observed EEG and SEP levels, each of the dichotomised decrease of EEG and SEP level, ICP, available treatment and clinical variables during hospitalization, and extent of the observation time (table VII). Regarding ICP in particular, we divided patients accordingly to ICP major values during the monitoring time, and in particular accordingly to ICP values $<20 \mathrm{mmHg}$, $20<\mathrm{ICP}<40 \mathrm{mmHg}$, and ICP $>40 \mathrm{mmHg}$. We selected the variables with a forward stepwise procedure by using the AIC criterion (Claeskens $\mathrm{G}$ et al). Note that differences between ICP $<20 \mathrm{mmHg}$ and $20<\mathrm{ICP}<40 \mathrm{mmHg}$ were not significant $(\mathrm{p}>0,05)$, so the two classes were collapsed. The overall fit of this model is quite good, since goodness-of-fit of Chi Square statistics is 47.87 on 62 degrees of freedom, giving a p-value of 0.9 . 


\begin{tabular}{|l|l|l|l|}
\hline Variable & Coefficient estimate & p-value & Odds \\
\hline Intercept & -6.1706 & 0.034 & 0.002 \\
\hline Age & 0.0914 & 0.040 & 1.096 \\
\hline ICP $>40 \mathrm{mmHg}$ & 6.5074 & 0.006 & 670.1 \\
\hline Duration (days) & -0.5866 & 0.020 & 0.556 \\
\hline $\begin{array}{l}\text { EEG, from first to third time } \\
\text { observation (worsened) }\end{array}$ & 3.1839 & 0.028 & 24.14 \\
\hline $\begin{array}{l}\text { SEP, from first to third time observation } \\
\text { (worsened) }\end{array}$ & 3.4769 & 0.005 & 32.36 \\
\hline
\end{tabular}

Table 7. Summary of the final logistic model for the probability of GOS 1

Considering the obtained estimates, when the EEG gets worse during the time of observation, the odds for dying increase of about $24 \%$ with respect to similar patients that did not get worse. SEP decrease is also significant: patients with worsening SEP show an odds-of-dying increase of about $32 \%$. Moreover, the longer the duration of hospitalization, the lower the risk of dying. Each day of hospitalization decreases the odds of dying of about $50 \%$.

To assess whether the inclusion of EEG and SEP variations in the model improves prediction, we compared ROC curves of four models: the final model including both EEG and SEP variations, the two models obtained by removing either EEG or SEP variations, respectively, and the model fitted removing both EEG and SEP variations.

The joint contribution of both variables was significant ( $p$-value for comparisons between ROC curves is 0.046) even if each variable alone does not seem to be significant ( $p$ value $=0.21$ for eliminating from the final model $E E G$ variation and $p$-value $=0.15$ for eliminating SEP variation).

Table VIII illustrates the coefficients and the p-values for the proportional odds model. As for the logistic model, we selected the most significant variables via a forward stepwise procedure considering the AIC index. Since very few patients showed GOS levels 2 and 5, we aggregated them to levels 3 and 4 respectively. Therefore, we obtained a three-level GOS.

\begin{tabular}{|l|l|l|l|}
\hline Variable & $\begin{array}{l}\text { Coefficient } \\
\text { estimated }\end{array}$ & p-value & exp(coefficient) \\
\hline Intercept 1|2 & -1.799 & $<0.001$ & 0.16 \\
\hline Intercept 2|3 & 2.156 & 0.015 & 8.63 \\
\hline CGS-M - worsened & -4.453 & $<0.001$ & 0.01 \\
\hline CGS-M - improved & 2.660 & 0.004 & 14.29 \\
\hline $\begin{array}{l}\text { SEP, from first to second time } \\
\text { observation (worsened) }\end{array}$ & -2.807 & 0.002 & 0.06 \\
\hline
\end{tabular}

Table 8. Summary of the proportional odds model.

Also this model has a good fit to data: Chi-square goodness-of-fit statistic is 85.86 on 131 degrees of freedom, giving a p-value of almost 1. Here, only modifications of GCS-M and SEP during hospitalization are significant to predict the GOS level. Patients showing worsening SEP during the last time interval are less likely $(1 / 20)$ to have a high GOS level than patients with stable SEP. Patients with a GCS-M getting worse during the entire 
observational period have a probability of a high GOS level of 1\%, if compared to patients with stable GCS-M. Moreover, an improved GCS-M increases the probability of a high GOS level of about 14 times (Table VII).

We also tested a model excluding the GCS-M modifications in time. However, it did not fit as well, showing the importance of GCS-M changes during hospitalization. It is interesting to observe that the initial SEP level and its changes during hospitalization, the changes of EEG in the last period of observation, and the presence of ICP higher than $40 \mathrm{mmHg}$ are significant variables when GCS-M is not considered, similarly to what we obtain with the logistic model.

It is worth noting that demographic variables, like age and sex, are not significant in any of the models used to predict the GOS level. They were not significant even when considered alone (Table V). The treatments effect is not significant neither in association with the other variables, nor when considered alone (Table V).

\section{Discussion}

Continuous EEG-SEP is a relatively new, non-invasive, bedside monitoring tool that allows a functional measurement of neurological impairment. There are two main advantages of clinical neurophysiology with respect to clinical examination:it can be employed in sedated and/or curarized patients, and it provides quantitative data for comparison with follow up studies. Compressed presentations like cerebral function monitor (CFM) or CDSA may help visualize these long term changes that are due to variations in the level of sedation. These tools, should be carefully used with the collaboration of a competent neurophysiologist. It should be kept in mind that,like any other clinical or technical examination,clinical neurophysiology only evaluates the current functional brain status, so that any prognostic information needs to be updated in case of eventual complication. Moreover, SEP trend is based on two simple parameters, amplitude and latency. Amplitude decrease and latency increase are dependent on the physiopathology of brain damage. Amplitude is related to the number of fibers carrying the signal to the primary somatosensory cortex. In the central nervous system, latency is mainly associated to white matter swelling. In the peripheral nervous system, it is related to temperature and focal myelin dysfunctions. There is good evidence that serial evoked potential studies provide useful information about the functional recovery of impaired areas [Amantini A et al.2008, Moulton RJ et al. 1998]. This is particularly true during the early post-injury stage, as SEP are a sensitive measure of secondary damage. Our results clearly show that SEP frequently change over time. The SEP-EEG deterioration is probably related to many different pathogenetic mechanisms: In the case of ischemia following vasospasm, SEP modifications precede $24-48$ hours ICP increasing (18 patients), in the case of brain oedema without hypoxic damage SEP modifications cames later (2 patients) The most likely explanation for this temporal sequence of events is that uncontrollable ICP may simply be a sign of large volumes of non-viable brain in fatally injured patients [Moulton RJ et al 1998]. A continuous SEP monitoring has a strong prognostic power, because amplitude modifications usually precede clinical manifestation of functional integrity. As continuous SEP monitoring reveal the potential for recovery, it can sometimes direct the physician towards a more aggressive clinical management. SEP provide important information about patients who are pharmacologically paralyzed and sedated to help ventilation and ICP management. In this setting, we have frequently 
relied on SEP measurement to direct the therapy. We discourage aggressive treatment (barbiturate coma, decompressive craniectomy) to control refractory ICP in patients who lost cortical SEP activity. Other investigators have also observed the absence of correlation between increased ICP and SEP deterioration. Focal injury results in primary damage to neurons and to the surrounding cerebral vessels. The secondary damage is due to ischemia and the cytotoxic cascade. Cytotoxic and vasogenic oedema in neurons leads to excitotoxic swelling. The SEP deterioration can have different timing, and it can occur before or after an ICP increase. Trends for ICP did not demonstrate a clear seizure-related effect on ICP or CPP in the hours directly before or during a seizure. The ICP always increased after vasospasm. Vasospasm is a primary source of neurologic co-morbidity after SAH. Trans-cranial Doppler ultrasounds (TCD) and cerebral angiography cannot be continuously performed; in contrast, EEG can constantly monitor the cerebral activity. In our series, the most sensitive QEEG monitoring parameter to detect seizures was CDSA. Seizures are often associated with transient increases in EEG power, although they have to be confirmed with the review of the raw EEG. Similarly, QEEG should never be interpreted without reviewing portions of the original waveforms. Most epileptiform activity occurred in the form of repetitive sharp waves. This activity shows a clear related predictive effect on vasospasm 24-48 hours in advance. QEEG data can be displayed with many methods [Jordan KG et al.1995, Rennie CJ et al 2002, Vespa PM et al. 1999]. CDSA depicts ictal and interictal data after a quantitative transformation of raw EEG data (Figure IV).
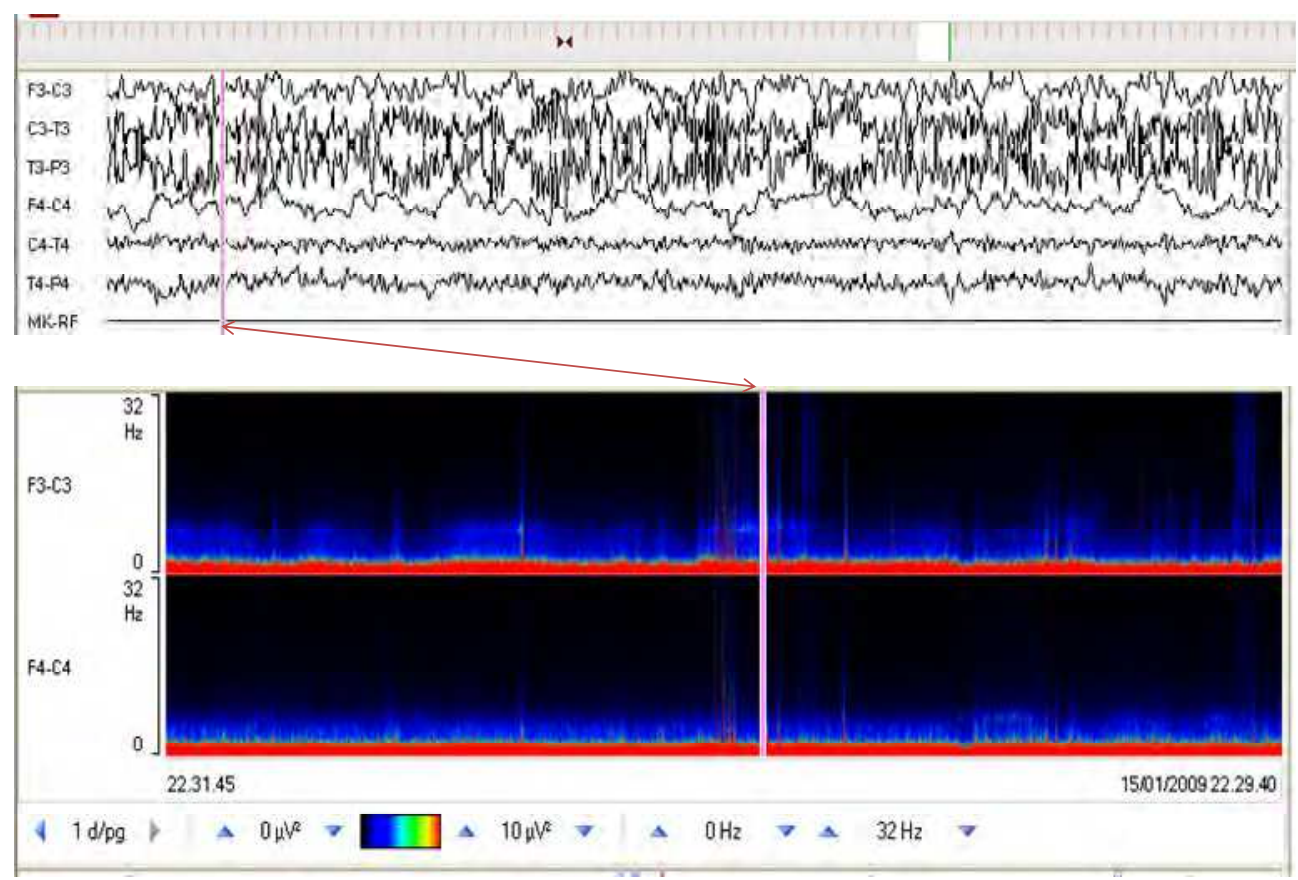

Fig. 4. The spectrogram shows high frequency activity : non convulsive status epilepticus 
Time is displayed on the $\mathrm{x}$-axis. The upper graph is a colour spectrogram showing averaged root EEG power from 0 to $32 \mathrm{~Hz}$ (y-axis), created from consecutive 10-second EEG epochs (each composed of five 2-second windows) obtained from F3-C3, F4-C4. The patient's repetitive seizures are now clear in the spectrogram as vertical bands of increased power. These graphs usually express power amplitude as a colour scale. Amplitude-integrated EEG graph can also provide a reasonable indication of the presence of suppression-burst activity. The somatosensory evoked potentials have not only a strong predictive power on outcome. They provide a feedback tool to modify and correct the treatment, according to the correlated neurological instability. If SEP are stable, the patient is neurologically stable even though ICP and CPP values are not in the normal range. Moreover, SEP can be pathological despite normal ICP and CPP values: in this case it is necessary to find the best ICP and CPP settings to re-establish "normal" evoked potentials values.

\section{Conclusions}

Our approach is based on the choice of an integrated EEG-SEP continuous monitoring,the respective parts of each test are individually evaluated,according to which one is likely to be more informative in these patients. SEP were always monitorable despite the frequent use of high level of neurosedation. As SEP monitoring shows high correlation with patient's outcome, it defines a measurable level of initial damage basing on the template SEP baseline, and on measurable parameters like amplitude and latency. The temporal variation of these two parameters, evaluated with the continuous monitoring, can confirm whether the treatment is tailored to the neurological changes induced by the lesion responsible for the secondary damage. The findings from our experience show that SEP worsening is independently associated with a poor outcome in patients with coma after intracranial hemorrhage. It is measured by specific parameters that quantify the damage and it replaces the clinical data that are often not quantifiable due both to the patient sedation and to the subjective evaluation performed by the physician. The precocious SEP deterioration can detect neurological impairment earlier than other hemodynamic variables like ICP and CPP, allowing the improving of the treatment. However it is not always possible to block the pathophysiological process, despite its early identification. In patients with SAH, the early changes in SEP amplitude allow a timely detection of initial vasospasm. QEEG changes preceded clinical evidence of vasospasm. cEEG use has documented a surprisingly high incidence of nonconvulsive seizures and nonconvulsive status epilepticus in patients with acute cerebral ischemia and intracranial hemorrhages. The combined use of SEP and continuous EEG monitoring is a unique example of dynamic-brain-monitoring.

\section{References}

Agresti A: Categorical Data Analysis, 2nd Edition. Wiley; 2002.

Amantini A, Amadori A, Fossi S: Evoked potentials in the ICU. Eur J Anaesthesiol Suppl 2008, 42:196-202.

Amantini A, Grippo A, Fossi S, Cesaretti C, Piccioli A, Peris A, Ragazzoni A, Pinto F: Prediction of "awakening" and outcome in prolonged acute coma from severe traumatic brain injury: evidence for validity of short latency SEP. Clin Neurophysiol 2005, 116:229-235. 
Bosco E, Marton E, Feletti A, Scarpa B, Longatti P, Zanatta P, Giorgi E, Sorbara C. Dynamic monitors of brain function: a new target in neurointensive care unit.Crit Care. 2011 Jul 15;15(4):R170.

Bullock R, Zauner A, Myseros JS, Marmarou A, Woodward JJ, Young HF: Evidence for prolonged release of excitatory amino acids in severe human head trauma. Relationship to clinical events. Ann N Y Acad Sci 1995, 765:290-297.

Chong DJ, Hirsch LJ. Which EEG patterns warrant treatment in the critically ill? Reviewing the evidence for treatment of periodic epileptiform discharges and related patterns. J Clin Neurophysiol 2005;22:79-91

Claassen J, Jette N, Chum F, Green R, Schmidt M, Choi H,Jirsch J, Frontera JA, Connolly ES, Emerson RG, Mayer SA,Hirsch LJ. Electrographic seizures and periodic discharges after intracerebral hemorrhage. Neurology 2007;69:1356-65.

Claassen J, Mayer SA, Kowalski RG, Emerson RG, Hirsch LJ.Detection of electrographic seizures with continuous EEG monitoring in critically ill patients. Neurology 2004;62:1743-8

Claeskens G, Hjort NL: Model selection and model averaging. Cambridge University Press; 2008.

DeLong, Elizabeth R., DeLong, David M., Clarke-Pearson Daniel L. (1988) Comparing the Areas under Two or More Correlated Receiver Operating Characteristic Curves: A Nonparametric Approach. Biometrics, Vol. 44, pp.837-845

DeLorenzo RJ, Waterhouse EJ, Towne AR, Boggs JG, Ko D,DeLorenzo GA, Brown A, Garnett L. Persistent nonconvulsive status epilepticus after the control of convulsive status epilepticus. Epilepsia 1998;39:833-40

Friedman D, ClassenJ, Hirsh LJ. Continuous electroencephalogram monitoring in the intensive care unit. Anesth Analg 2009;109:506-523

Grände PO, Asgeirsson B, Nordström CH. Volume-targeted therapy of increased intracranial pressure: the Lund concept unifies surgical and non-surgical treatments.Acta Anaesthesiol Scand. 2002 Sep;46(8):929-41. Review

Greenberg RP, Mayer DJ, Becker DP, Miller JD: Evaluation of brain function in severe human head trauma with multimodality evoked potentials, methods and analysis. J Neurosurg 1977, 47:150-162.

Jennett B, Bond M: Assessment of outcome after severe brain damage. Lancet 1975, 7905:480484.

Jette N, Claassen J, Emerson RG, Hirsch LJ. Frequency and predictors of nonconvulsive seizures during continuous electroencephalographic monitoring in critically ill children. Arch Neurol 2006;63:1750-5

Jordan KG: Neurophysiologic monitoring in the neuroscience intensive care unit. Neurol Clin 1995, 13:579-626.

Miller JD, Piper IR, Jones PA: Integrated multimodality monitoring in the neurosurgical intensive care unit. Neurosurg Clin N Am 1994, 5:661-670.

Moulton RJ, Brown JI, Konasiewicz SJ: Monitoring severe head injury: a comparison of EEG and somatosensory evoked potentials. Can J Neurol Sci 1998, 25:S7-S11.

Oddo M, Carrera E, Classen J, Mayer SA, Hirsch LJ. Continuous electroencephalography in the medical intensive care unit. Crit Care Med 2009;37:2051-2056 
Pandian JD, Cascino GD, So EL, Manno E, Fulgham JR. Digital videoelectroencephalographic monitoring in the neurologicalneurosurgical intensive care unit: clinical features and outcome. Arch Neurol 2004;61:1090-4

Rennie CJ, Robinson PA, Wright JJ: Unified neurophysical model of EEG spectra and evoked potentials. Biol Cybern 2002, 86:457-471.

Rose J, Valtonen S, Jennett B: Avoidable factors contributing to death after head injury. Br Med J 1977, 2:615-618.

Rosner MJ, Coley IB. J Cerebral perfusion pressure, intracranial pressure, and head elevation Neurosurg. 1986 Nov;65(5):636-41.

Synek VM: Prognostically important EEG coma pattern in diffuse anoxic and traumatic encephalopathies in adults. J Clin Neurophysiol 1988, 5:161-174.

Vespa PM, McArthur D, O'Phelan K, Glenn T, Etchepare M, Kelly D, Bergsneider M, Martin NA, Hovda DA: Persistently low extracellular glucose correlates with poor outcome 6 months after human traumatic brain injury despite a lack of increased lactate: a microdialysis study. J Cereb Blood Flow Metab 2003, 23:865-877.

Vespa PM, Nenov V, Nuwer MR: Continuous EEG monitoring in the intensive care unit: early findings and clinical efficacy. J Clin Neurophysiol 1999, 16:1-13.

Young GB, Lachlan MC, Kreeft JH and Demelo JD.An Electroencephalographic Classification for Coma. Can.J.Neurol.Sci.1997;24:320-32 


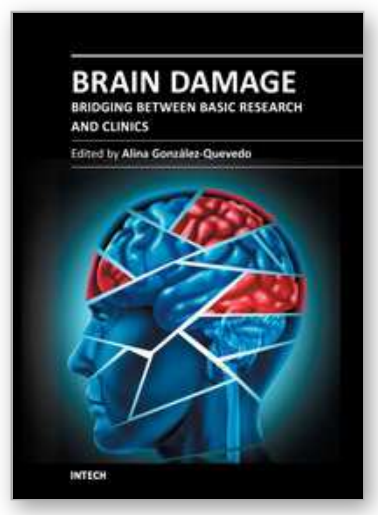

\author{
Brain Damage - Bridging Between Basic Research and Clinics \\ Edited by Dr. Alina Gonzalez-Quevedo
}

ISBN 978-953-51-0375-2

Hard cover, 282 pages

Publisher InTech

Published online 16, March, 2012

Published in print edition March, 2012

"Brain Damage - Bridging Between Basic Research and Clinics" represents a collection of papers in an attempt to provide an up-to-date approach to the fascinating topic of brain damage in different pathological situations, combining the authors' personal experiences with current knowledge in this field. In general, the necessary link between basic and clinical neurosciences is highlighted, as it is through this interaction that the theoretical understanding of the pathophysiological mechanisms can be successfully translated into better ways to diagnose, treat and prevent the catastrophic events that occur when the brain suffers from external or internal noxious events. The book spans different aspects of brain injury, starting from damage occurring in the fetal and child brain, followed by different neurodegenerative processes. Attention is also focused on the negative effects of drug addictions and sleep deprivation on the brain, as well as on the early assessment of brain injury for preventive strategies employing sensitive biomarkers.

\title{
How to reference
}

In order to correctly reference this scholarly work, feel free to copy and paste the following:

E. Bosco and P. Zanatta (2012). Dynamic Brain Function Monitoring a New Concept in Neuro-Intensive Care, Brain Damage - Bridging Between Basic Research and Clinics, Dr. Alina Gonzalez-Quevedo (Ed.), ISBN: 978953-51-0375-2, InTech, Available from: http://www.intechopen.com/books/brain-damage-bridging-betweenbasic-research-and-clinics/dynamic-brain-function-monitoring-a-new-concept-in-neuro-intensive-care

\section{INTECH}

open science | open minds

\section{InTech Europe}

University Campus STeP Ri

Slavka Krautzeka 83/A

51000 Rijeka, Croatia

Phone: +385 (51) 770447

Fax: +385 (51) 686166

www.intechopen.com

\section{InTech China}

Unit 405, Office Block, Hotel Equatorial Shanghai

No.65, Yan An Road (West), Shanghai, 200040, China

中国上海市延安西路65号上海国际贵都大饭店办公楼 405 单元

Phone: +86-21-62489820

Fax: $+86-21-62489821$ 
(C) 2012 The Author(s). Licensee IntechOpen. This is an open access article distributed under the terms of the Creative Commons Attribution 3.0 License, which permits unrestricted use, distribution, and reproduction in any medium, provided the original work is properly cited. 